Published in final edited form as:

Chem Res Toxicol. 2007 March ; 20(3): 531-542.

\title{
A Comprehensive Investigation of 2-Amino-1-methyl-6- phenylimidazo[4,5-b]pyridine (PhIP) Metabolism in the Mouse Using a Multivariate Data Analysis Approach
}

\author{
Chi Chen ${ }^{\dagger}$, Xiaochao Ma ${ }^{\dagger}$, Michael A. Malfatti ${ }^{\ddagger}$, Kristopher W. Krausz ${ }^{\dagger}$, Shioko Kimura ${ }^{\dagger}$, \\ James S. Felton $\ddagger$, Jeffrey R. Idle $§$, and Frank J. Gonzalez ${ }^{\star}, \dagger$ \\ †Laboratory of Metabolism, Center for Cancer Research, National Cancer Institute, National \\ Institutes of Health, Bethesda, Maryland 20892
}

$\ddagger$ Biosciences Directorate, Lawrence Livermore National Laboratory, Livermore, California

$\S$ Institute of Pharmacology, 1st Faculty of Medicine, Charles University, Prague, Czech Republic

\begin{abstract}
2-Amino-1-methyl-6-phenylimidazo[4,5- $b$ ]pyridine (PhIP) is a potent rodent carcinogen and a potential human carcinogen because of its existence in the normal human diet. $N^{2}-\mathrm{OH}-\mathrm{PhIP}$, a major PhIP metabolite, has been identified as a precursor of genotoxic species. In vitro data supported the view that CYP1A2 is the major enzyme responsible for the formation of $N^{2}-\mathrm{OH}-\mathrm{PhIP}$. However, disruption of the CYP1A2 gene in mouse failed to inhibit PhIP-induced carcinogenesis. To investigate the mechanism underlying this observation, the metabolism of PhIP in wild-type, Cyp1a2-null, and CYP1A2-humanized mice was examined in detail using a metabolomic approach. Following data acquisition in a high-resolution LCMS system, urinary metabolomes of the control and PhIP-treated mice were characterized in a principal component analysis (PCA) model. Comprehensive metabolite profiles of PhIP in high dose $(10 \mathrm{mg} / \mathrm{kg})$ and low dose $(100 \mu \mathrm{g} / \mathrm{kg})$ were established through analyzing urinary ions contributing to the separation of three mouse lines in the multivariate model and by measuring radiolabled PhIP metabolite in a radio-HPLC assay, respectively. The genotoxicity of PhIP to three mouse lines was evaluated by measuring DNA adduction levels in liver, lung, colon, and mammary gland. On the basis of the chemical identities of 17 urinary PhIP metabolites, including eight novel metabolites, multivariate data analysis revealed the role of CYP1A2 in PhIP metabolism and a human-mouse interspecies difference in the catalytic activity of CYP1A2. In addition, the results also showed that Cypla2-null mice still possess significant $N^{2-}$ hydroxylation and DNA adduction activities, which may be partially attributed to mouse CYP2C enzymes according to the results from in vitro microsome and Supersome incubations and antibody inhibition experiments.
\end{abstract}

\section{Introduction}

2-Amino-1-methyl-6-phenylimidazo[4,5-b]pyridine (PhIP) ${ }^{1}$ is one of the most abundant heterocyclic amines (HCA) formed in the process of cooking meat and is also found in beer, wine, and cigarette smoke (1). Detection of PhIP and its metabolites in the urine of people eating a normal Japanese diet as well as in smokers of black tobacco demonstrated extensive human exposure $(2,3)$. Induction of carcinomas in rodent lymph, mammary gland, and colon further strengthened its candidacy as a human carcinogen $(4,5)$. It is known that PhIP must first

\footnotetext{
* To whom correspondence should be addressed. Tel: 301-496-9067. Fax: 301-496-8419. E-mail: fjgonz@ helix.nih.gov.

Supporting Information Available: LC-MS/MS structural elucidation of urinary PhIP metabolites. This material is available free of charge via the Internet at http://pubs.acs.org.
} 
be oxidized by cytochrome $\mathrm{P} 450$ ( $\mathrm{P} 450$ ) and then activated by conjugation enzymes such as $\mathrm{N}$-acetyltransferases (6) and sulfotransferases before eliciting its genotoxicity (7). The generation of a DNA-reactive nitrenium cation has been recognized as an essential step in the process of forming PhIP-DNA adducts.

The metabolism of PhIP has been studied extensively by using rodent and nonhuman primate animal models (8) as well as in vitro models (9). Major oxidation metabolites of PhIP are $\mathrm{N}^{2-}$ hydroxy-PhIP (OH-PhIP) and 4'-OH-PhIP. Recently, 5-OH-PhIP was identified in mouse urine, and its formation was suggested to be through a P450-independent pathway $(10,11)$. Detoxification of reactive $N^{2}-\mathrm{OH}-\mathrm{PhIP}$ is mainly mediated by glucuronidation pathways to form $N^{2}$-OH-PhIP- $N^{2}$-glucuronide and $N^{2}$-OH-PhIP- $N 3$-glucuronide $(12,13)$, although both glucuronidation and sulfation reactions contribute to the elimination of 4'-OH-PhIP. Because of its high abundance in both human and rodent livers and its high catalytic activity as a PhIP$N^{2-}$ hydroxylase (14), CYP1A2 was suggested as an essential enzyme for the bioactivation of $\mathrm{PhIP}$. However, we recently reported comparable tumorigenesis in both wild-type and Cypla2-null mice after PhIP treatment, which implied the existence of CYP1A2-independent bioactivation pathways (15).

Metabolomics, as a rapidly evolving tool in systems biology, aims to define small-molecule metabolomes in cells, tissues, and organisms and to monitor the changes following genetic modification or exogenous challenges $(16,17)$. Because multivariate data analysis (MDA), the data-processing platform of metabolomics, possesses the capacity of detecting subtle changes

\footnotetext{
${ }^{1}$ Abbreviations:

PhIP

2-amino-1-methyl-6-phenylimidazo[4,5-b]pyri-dine

P450

cytochrome P450

PCA

principal components analysis

PLSDA

partial least-squares-discriminant analysis

MDA

multivariate data analysis

MLM

mouse liver microsomes

HLM

human liver microsomes

MS $^{2}$

tandem mass spectrometry

LC-MS/MS

liquid chromatography-tandem mass spectrometry

UPLC

ultraperformance liquid chromatography

TOF-MS

time-of-flight mass spectrometry

OH-PHIP

hydroxy-PhIP

mAb

monoclonal antibody
} 
in a large data set, the potential application of MDA in drug metabolism and chemical toxicology has been illustrated (18). However, the power of MDA in solving problems in both fields has not been fully explored.

To elucidate the role of CYP1A2 in PhIP-induced carcino-genesis, the metabolism of PhIP in wild-type, Cypla2-null, and CYP1A2-humanized mice was examined in detail in this study through a metabolomic approach, and tissue-specific DNA adduction caused by the bioactivation of PhIP was measured. In addition, the role of other P450s in PhIP metabolism was also investigated.

\section{Experimental Procedures}

\section{Chemicals and Reagents}

$\mathrm{PhIP}$ and $N^{2}-\mathrm{OH}-\mathrm{PhIP}$ were obtained from the National Cancer Institute Chemical Carcinogen Reference Standard Repository at the Midwest Research Institute (Kansas City, MO). 4'-OHPhIP was kindly provided by Dr. Minako Nagao (National Cancer Research Center, Tokyo, Japan). $\left[{ }^{14} \mathrm{C}\right] \mathrm{PhIP}$ was purchased from Toronto Research Chemicals (North York, Ontario, Canada). The radiochemical purity of $\left[{ }^{14} \mathrm{C}\right] \mathrm{PhIP}$ was determined to be $>98 \%$ pure by HPLC (isocratic at $40 \%$ methamol). HPLC-grade acetonitrile, methanol, and formic acid as well as $\beta$-nicotinamide adenine dinucleotide ( $\beta$-NADPH) were purchased from Sigma (St. Louis, MO). Pooled human liver microsomes (HLM) and recombinant human P450 enzymes (CYP1A1, 1A2, 1B1, 2A6, 2B6, 2C8, 2C9, 2C18, 2C19, 2D6, 2E1, and 3A4) from baculovirusinfected insect cells were purchased from either BD Biosciences Genetest (San Jose, CA) or Invitrogen Panvera (Carlsbad, CA).

\section{Animals}

Both the Cypla2-null mouse line (mCyp1a2-/-) and the CYP1A2- humanized mouse line on a Cypla2-null background ( $h$ CYP1A2+/+, mCypla2-/-) were described previously $(19,20)$. Wild-type mice (mCypla2+/+) on a 129/Sv strain background were used in this study. All

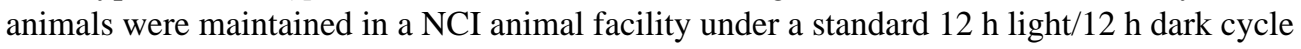
with food and water ad libitum. Handling and treatment procedures were in accordance with animal study protocols approved by the NCI Animal Care and Use Committee.

\section{In Vivo Metabolism of PhIP in Mice}

Four male mice from each genotype group, age 8-12 weeks, were used for urinary metabolite profiling. Urine samples were collected by housing mice for $24 \mathrm{~h}$ in glass metabolic bowls (Jencons, Leighton Buzzard, United Kingdom), urine volumes were recorded, and the urines were stored frozen at $-80{ }^{\circ} \mathrm{C}$ before analysis. Two days prior to $\mathrm{PhIP}$ treatment, control urine samples were collected after dosing mice with corn oil vehicle (100 $\mu \mathrm{L} / 10 \mathrm{~g})$. PhIP (suspended in corn oil) was administrated by oral gavage in a $10 \mathrm{mg} / \mathrm{kg}$ dose. After urine collection, mice were sacrificed and the tissues were harvested and snap-frozen in liquid nitrogen before storage at $-80{ }^{\circ} \mathrm{C}$. Samples for ultraperformance liquid chromatography (UPLC)-time-of-flight mass spectrometry (TOF-MS) analysis were prepared by mixing $50 \mu \mathrm{L}$ of urine with $200 \mu \mathrm{L}$ of $50 \%$ aqueous acetonitrile and centrifuging at $18000 \mathrm{~g}$ for $5 \mathrm{~min}$ to remove protein and particulates. A $200 \mu \mathrm{L}$ aliquot of the supernatant was transferred to an autosampler vial for further analysis.

For the radioactivity study, mice received $100 \mu \mathrm{g} / \mathrm{kg}\left[{ }^{14} \mathrm{C}\right] \mathrm{PhIP}(6.3 \mu \mathrm{Ci} / \mathrm{kg})$ in corn oil by oral gavage. Urine samples were collected in metabolic cages for $24 \mathrm{~h}$. Tissue samples were harvested after urine collection. 


\section{In Vitro Metabolism of PhIP in Mouse Liver Microsomes (MLMs) and HLM}

Livers from untreated wild-type, Cypla2-null, and CYP1A2-humanized mice were homogenized, and microsomes were prepared as described previously (21). Microsomal incubations were carried out in $20 \mathrm{mM}$ phosphate-buffered saline (PBS), $\mathrm{pH} 7.4$, containing $0.5 \mathrm{mg} / \mathrm{mL}$ microsomal protein, $2 \mathrm{mM} \mathrm{MgCl} 2,10 \mu \mathrm{M} \mathrm{PhIP}$, and $1 \mathrm{mg} / \mathrm{mL}$ freshly prepared $\beta$ NADPH in a final volume of $200 \mu \mathrm{L}$. After a $20 \mathrm{~min}$ incubation at $37^{\circ} \mathrm{C}$, the reaction mix was directly loaded into a pretreated Oasis column (Waters, Milford, MA) and washed with $1 \mathrm{~mL}$ of water, and metabolites were eluted with $1 \mathrm{~mL}$ of methanol. The extract was dried under $\mathrm{N}_{2}$ and reconstituted in 50\% aqueous acetonitrile for liquid chromatography-tandem mass spectrometry (LC-MS/MS) analysis.

\section{In Vitro Metabolism of PhIP by Recombinant Human P450 Isozymes}

Reactions were carried out in $20 \mathrm{mM}$ PBS, $\mathrm{pH} 7.4$, containing $20 \mathrm{nM}$ recombinant human $\mathrm{P} 450 \mathrm{~s}, 2 \mathrm{mM} \mathrm{MgCl} 2,10 \mu \mathrm{M} \mathrm{PhIP}$, and $1 \mathrm{mg} / \mathrm{mL}$ freshly prepared $\beta$-NADPH in a final volume of $200 \mu \mathrm{L}$. After $20 \mathrm{~min}$ of incubation at $37^{\circ} \mathrm{C}$, samples for LC-MS/MS analysis were prepared under the same conditions as described above.

\section{Enzyme Kinetics of Recombinant Human CYP1A2 and CYP2C19 Isozymes}

PhIP ranging from 1 to $500 \mu \mathrm{M}$ was incubated with recombinant human CYP1A2 and CYP2C19 isozymes for 20 min under the same conditions as described above. Kinetic parameters, $K_{\mathrm{m}}$ and $V_{\max }$, for the formation of 4'-OH-PhIP and $N^{2}-\mathrm{OH}-\mathrm{PhIP}$ were evaluated by nonlinear regression (Prism GraphPad 2.0, San Diego, CA).

\section{Antibody Inhibition of PhIP Metabolism}

In contrast to the aforementioned conditions for microsomal incubation, $5 \mu \mathrm{L}$ of mouse CYP1A2 [monoclonal antibody (mAb) 1-7-1] (22) and rat CYP2C11 (mAb 1-68-11) (23) monoclonal antibodies was preincubated with the microsomes for $5 \mathrm{~min}$ before adding PhIP and $\beta$-NADPH. Reactions were terminated at $20 \mathrm{~min}$, and samples were processed under the same conditions as described above.

\section{LC-ESI-MS/MS Analysis of PhIP Metabolites}

For LC-MS analysis, a $5 \mu \mathrm{L}$ aliquot of samples from mouse urine or in vitro incubation was injected into a Waters UPLC-QTOF-MS system (Mildford, MA). An Acquity UPLC BEH $\mathrm{C}_{18}$ column (Waters) was used to separate $\mathrm{PhIP}$ and its metabolites at $30^{\circ} \mathrm{C}$. The mobile phase flow rate was $0.5 \mathrm{~mL} / \mathrm{min}$ with a gradient ranging from water to $95 \%$ aqueous acetonitrile containing $0.1 \%$ formic acid over a 10 min run. The QTOF Premier mass spectrometer was operated in the positive electrospray ionization (ESI) mode. The capillary voltage and cone voltage were maintained at $3 \mathrm{kV}$ and $20 \mathrm{~V}$, respectively. The source temperature and desolvation temperature were set at 120 and $350{ }^{\circ} \mathrm{C}$, respectively. Nitrogen was used as both the cone gas $(50 \mathrm{~L} / \mathrm{h})$ and the desolvation gas $(600 \mathrm{~L} / \mathrm{h})$, and argon was used as the collision gas. For accurate mass measurement, the QTOF-MS was calibrated with sodium formate solution (range $\mathrm{m} / \mathrm{z}, 100-1000$ ) and monitored by the intermittent injection of the lock mass sulfadimethoxine $\left([\mathrm{M}+\mathrm{H}]^{+}=311.0814 \mathrm{~m} / z\right)$ in real time. Mass chromatograms and mass spectral data were acquired by MassLynx software in centroided format and were further processed by MetaboLynx software to screen and identify potential PhIP metabolites through the mass difference from the PhIP protonated molecular ion $\left([\mathrm{M}+\mathrm{H}]^{+}=225.1140 \mathrm{~m} / \mathrm{z}\right)$. The structure of each PhIP metabolite was elucidated by tandem mass spectrometry $\left(\mathrm{MS}^{2}\right)$ fragmentation with a collision energy ranging from 15 to $35 \mathrm{eV}$. 


\section{Data Processing and Principal Components Analysis (PCA)}

Following UPLC-TOF-MS data acquisition on the control and PhIP-treated urine samples, chromatographic and spectral data were first centroided and integrated and then deconvoluted by MarkerLynx software (Waters) to generate a multivariate data matrix. The intensity of each ion was calculated as the percentage of total ion counts in the whole chromatogram. The data matrix was further exported into SIMCA-P+ software (Umetrics, Kinnelon, NJ) and transformed by mean-centering and Pareto scaling, a technique that increased the importance of low abundance ions without significant amplification of noise. Principal components were generated by PCA analysis to represent the major latent variables in the data matrix and were described in a scores scatter plot. Potential PhIP metabolites were identified by analyzing ions contributing to the principal components and to the separation of sample groups in the loadings scatter plot.

\section{Analysis of Radiolabeled PhIP Metabolites in Mouse Urine}

Collected urine was thawed, and the total volume of each fraction was recorded. A $0.5 \mathrm{~mL}$ aliquot from each fraction was analyzed for ${ }^{14} \mathrm{C}$ content by liquid scintillation counting (Wallic, Gaithersburg, MD). A $0.5 \mathrm{~mL}$ aliquot of each urine sample was then analyzed by reversedphase HPLC for PhIP and PhIP metabolites by directly injecting the samples onto a Rainin HPLC system (Varian, Walnut Creek, CA) equipped with a $5 \mu \mathrm{m}, 4.6 \mathrm{~mm} 150 \mathrm{~mm}$ TSK-GEL ODS-80 TM C18 column (Tosoh Bioscience, $\times$ Montgomeryville, PA) and monitored at 315 $\mathrm{nm}$. Metabolites were eluted at $0.75 \mathrm{~mL} / \mathrm{min}$ initially using a solvent of $10 \%(\mathrm{v} / \mathrm{v})$ methanol/ $0.1 \%(\mathrm{v} / \mathrm{v})$ triethylamine ( $\mathrm{pH} 6)$, for $2 \mathrm{~min}$. This was followed by a gradient to $33 \%(\mathrm{v} / \mathrm{v})$ methanol $/ 0.1 \%$ triethylamine at $32 \mathrm{~min}$, followed by a final gradient to $55 \%(\mathrm{v} / \mathrm{v})$ methanol/ $0.1 \%$ triethylamine at $60 \mathrm{~min}$. The methanol concentration was maintained at $55 \%(\mathrm{v} / \mathrm{v})$ from 60 to $70 \mathrm{~min}$. The column eluate was collected at $1 \mathrm{~min}$ intervals, and the radioactivity was quantified by scintillation counting. The radiolabled PhIP metabolites were identified through the comparison with authentic standards.

\section{DNA Isolation and Adduct Analysis}

DNA isolation from mouse liver, lung, colon, and mammary gland and sample preparation for the quantification of DNA adduct levels by accelerator mass spectrometer (AMS) have been reported previously (12). Briefly, tissues were homogenized and then digested in lysis buffer (4 M urea, 1.0\% Triton X-100, $10 \mathrm{mM}$ EDTA, $100 \mathrm{mM} \mathrm{NaCl}, 10 \mathrm{mM}$ DTT, and $10 \mathrm{mM}$ Tris$\mathrm{HCl}, \mathrm{pH} 8.0$ ) containing $0.8 \mathrm{mg} / \mathrm{mL}$ proteinase $\mathrm{K}$ overnight at $37^{\circ} \mathrm{C}$. Undigested tissue was removed by centrifugation, and the supernatant was treated for $1 \mathrm{~h}$ at room temperature with RNase A $(0.5 \mathrm{mg} / \mathrm{mL})$ and RNase T1 $(5 \mu \mathrm{g} / \mathrm{mL})$. DNA was extracted using Qiagen column chromatography (Qiagen, Valencia, CA) according to the manufacturer's instructions. DNA purity was determined by the $A_{260 \mathrm{~nm}} / A_{280 \mathrm{~nm}}$ ratio. A ratio between 1.6 and 1.8 indicated DNA purity. Pure DNA samples were submitted for adduct analysis by AMS.

\section{Statistics}

Experimental values are expressed as means \pm standard deviations (SDs). Statistical analysis was performed with two-tailed Student's $t$ tests for unpaired data, where a $P$ value of $<0.01$ was considered statistically significant.

\section{Results \\ Metabolomic Comparison of Urine Samples from Wild-Type, Cyp1a2-Null, and CYP1A2- Humanized Mice Treated with PhIP}

To elucidate the metabolism profile of PhIP at a carcinogenic dose, wild-type, Cypla2-null, and CYP1A2- humanized mice were treated with $10 \mathrm{mg} / \mathrm{kg}$ of PhIP. Control and PhIP-treated 
urine samples were separated by the UPLC system, and urinary components were detected by a high-resolution TOF mass spectrometer. After acquired data were processed by an unsupervised PCA, a three-component PCA model $\left(R^{2}=0.568, Q^{2}=0.402\right)$ was constructed to depict metabolomic profiles of control and PhIP-treated urines from three mouse lines (Figure 1). As shown in the scores scatter plot (Figure 1A), while control samples from three mouse lines were close to each other in the model, PhIP treatment led to the distinctive separation of urine samples according to their genotypes, which indicated that the chemical composition of urine samples from all three mouse lines was affected differentially by $\mathrm{PhIP}$ and its metabolites. One distinguishing feature of the PhIP-induced metabolomic changes was that as wild-type and humanized mice shifted away from their respective controls, mainly in the first two principal components ( $t[1]$ and $t$ [2]), Cypla2-null mice also distanced themselves from the control in the third component $(t[3])$ of the PCA model after PhIP treatment, indicating that the PhIP metabolism in Cypla2- null mice may significantly differ from its metabolism in wild-type and humanized mice. To understand this phenomenon, the contribution of each ion to all three principal components was examined in a loadings scatter plot (Figure 1B), in which the spatial position of each ion corresponds to its weights or loading values to principal components ( $p[1], p[2]$, and $p[3])$. Because PhIP and its metabolites can only be detected in treated samples, a group of $\mathrm{PhIP}$ metabolite candidates were identified through examining ions that contributed heavily to the separation between control and treated samples, and their accurate masses were subsequently measured. Mass differences between them and the PhIP parent ion indicated that the seurinary PhIP metabolites originated from hydroxylation, methylation, glucuronidation, and sulfation reactions, either separately or collectively.

\section{Identification and Structural Elucidation of Urinary Metabolites of PhIP}

To achieve an exhaustive detection and a comprehensive coverage of urinary metabolites of $\mathrm{PhIP}$, a software-assisted metabolite screening (as described in the Experimental Procedures) was conducted based on the data from MDA and accurate mass measurement. Values of theoretical mass changes caused by the common metabolizing reactions were used as the criteria for identifying metabolites from the PhIP-treated samples. After the screening, structural identities of urinary PhIP metabolites were further elucidated based on the fragmentation information obtained from $\mathrm{MS}^{2}$ analysis and current knowledge on the fragmentation pattern and retention time of PhIP metabolites in LC-MS analysis. Overall, $\mathrm{PhIP}$ (I) and 17 metabolites were identified in the urine samples from three mouse lines. Nine of them (III, IV, V, VII, XI, XII, XIII, XVI, and XVII) are known metabolites, and eight of them (II, VI, VIII, IX, X, XIV, XV, and XVIII) are novel metabolites. Major $\mathrm{MS}^{2}$ fragment ions and retention time (RT) of PhIP metabolites are enlisted and interpreted as follows, and $\mathrm{MS}^{2}$ spectra of six new metabolites (II, VI, IX, X, XIV, and XV) are presented in Figure 2AF (MS ${ }^{2}$ spectra of I, III, IV, V, VII, VIII, XI, XII, XIII, XVI, XVII, and XVIII in the Supporting Information, Figure 1A-L).

I. $\mathrm{PhIP}(3.95 \mathrm{~min}): 225.117^{+}$(parent ion), $210.091^{+}\left(-\mathrm{CH}_{3}\right), 209.083^{+}\left(-\mathrm{NH}_{2}\right)$, $183.082^{+}\left(-\mathrm{CHdN}\right.$ from $\left.210.091^{+}\right), 182.078^{+}\left(-\mathrm{CHdN}\right.$ from $\left.209.083^{+}\right), 168.070^{+}(-$ $\mathrm{NH}_{2}$ from $183.082^{+}$or $-\mathrm{CH}_{3}$ from $182.078^{+}$). The identity of PhIP in urine was also confirmed by comparison with the authentic standard.

II. $N^{2}$-methyl-PhIP (4.51 min, Figure 2A): $239.130^{+}$(parent), $224.102^{+}\left(-\mathrm{CH}_{3}\right.$ from $N 1$ position); $223.099^{+}, 196.089^{+}$, and $179.070^{+}$potentially originated from the structural rearrangement of imidazole ring to pyrazine ring, which is similar to $N^{2}-\mathrm{OH}-\mathrm{PhIP}$ (IV).

III. 4'-OH-PhIP (2.81 min): $241.115^{+}$(parent ion), $226.083^{+}\left(-\mathrm{CH}_{3}\right), 225.081^{+}\left(-\mathrm{NH}_{2}\right)$, $198.084^{+}\left(-\mathrm{CO}\right.$ from $\left.226.083^{+}\right)$. The identity of $4^{\prime}-\mathrm{OH}-\mathrm{PhIP}$ in urine was also confirmed by comparison with the authentic standard. 
IV. $N^{2}$-OH-PhIP (3.83 min): $223.100^{+}\left(-\mathrm{H}_{2} \mathrm{O}\right)$; ions $206.072^{+}, 196.084^{+}$and $179.064^{+}$ were potentially generated through the rearrangement of imidazole ring to pyrazine ring, as described in the Supporting Information (Figure 1C). The identity of $N^{2-} \mathrm{OH}-$ $\mathrm{PhIP}$ in urine was also confirmed by comparison with the authentic standard.

V. 5-OH-PhIP (4.07 min): $241.112^{+}$(parent ion), $226.082^{+}\left(-\mathrm{CH}_{3}\right), 223.104^{+}\left(-\mathrm{H}_{2} \mathrm{O}\right)$, $196.074^{+}\left(-\mathrm{CHdN}\right.$ from $\left.223.094^{+}\right)$. The fragmentation pattern of metabolite $\mathbf{V}$ was consistent with the reported 5-OH-PhIP fragmentation pattern (9).

VI. $N^{2}$-methyl-4'-OH-PhIP (3.20 min, Figure 2B): $255.125^{+}$(parent ion), $240.097^{+}(-$ $\left.\mathrm{CH}_{3}\right) ; 239.094^{+}, 212.083^{+}$, and $195.060^{+}$were generated by ring rearrangement similar to $N^{2-}$ methyl-PhIP (II) and $N^{2}$-OH-PhIP (IV). $4^{\prime}$-Hydroxylation was assumed after excluding $N^{2}$ - and 5-hydroxylation through examination of the $\mathrm{MS}^{2}$ fragments.

VII.4'-OH-PhIP sulfate (2.59 min): $321.065^{+}$(parent ion), $241.109^{+}\left(-\mathrm{SO}_{3}\right), 226.088^{+}$($\mathrm{CH}_{3}$ from 241.109$), 213.111^{+}\left(-\mathrm{C}=\mathrm{O}\right.$ from $\left.241.109^{+}\right)$.

VIII5-OH-PhIP sulfate (2.87 min): $321.067^{+}$(parent ion), $241.108^{+}\left(-\mathrm{SO}_{3}\right), 226.084^{+}$($\mathrm{CH}_{3}$ from $\left.241.109^{+}\right), 196.068^{+}\left(-\mathrm{H}_{2} \mathrm{O}\right.$ and $-\mathrm{CHdN}$ from $\left.223.094^{+}\right)$.

IX. $N^{2}, 4^{\prime}$-diOH-PhIP sulfate (2.47 min, Figure 2C): $337.066^{+}$(parent ion), $320.056^{+}(-$ $\mathrm{OH}), 257.105^{+}\left(-\mathrm{SO}_{3}\right), 239.092^{+}\left(-\mathrm{H}_{2} \mathrm{O}\right.$ from $\left.257.105^{+}\right), 228.101^{+}(-\mathrm{CHO}$ from $\left.257.105^{+}\right)$.

X. 5,4'-DiOH-PhIP sulfate (2.67 min, Figure 2D): $337.058^{+}$(parent ion), $257.102^{+}(-$ $\left.\mathrm{SO}_{3}\right), 242.081^{+}\left(-\mathrm{CH}_{3}\right.$ from $\left.257.101^{+}\right), 228.102^{+}\left(-\mathrm{CHO}\right.$ from $\left.257.101^{+}\right)$.

XI. PhIP-N3-glucuronide (3.21 min): $401.142^{+}$(parent ion), $225.117^{+}\left(-\mathrm{C}_{6} \mathrm{H}_{8} \mathrm{O}_{6}\right)$.

XII.PhIP- $N^{2}$-glucuronide (3.72 min): $401.148^{+}$(parent ion), $225.116^{+}\left(-\mathrm{C}_{6} \mathrm{H}_{8} \mathrm{O}_{6}\right)$. Identities of metabolites XI and XII were assigned based on their RT since previous studies showed that PhIP-N3-glucuronide had a shorter RT than PhIP- $N^{2}$-glucuronide $(24,25)$.

XIII4'-OH-PhIP glucuronide (2.19 min): $417.147^{+}$(parent ion), $241.110^{+}\left(-\mathrm{C}_{6} \mathrm{H}_{8} \mathrm{O}_{6}\right)$, $226.072^{+}\left(-\mathrm{CH}_{3}\right.$ from $\left.241.110^{+}\right)$.

XIV5-OH-PhIP glucuronide (2.89 min, Figure 2E): $417.142^{+}$(parent ion), $241.111^{+}$($\left.\mathrm{C}_{6} \mathrm{H}_{8} \mathrm{O}_{6}\right), 223.102^{+}\left(-\mathrm{H}_{2} \mathrm{O}\right.$ from $\left.241.107^{+}\right), 196.086^{+}\left(-\mathrm{CHdN}\right.$ from $\left.223.102^{+}\right)$.

XV.4'-OH-PhIP- $N^{2}$-glucuronide (3.10 min, Figure 2F): $417.137^{+}$(parent ion), $241.111^{+}$ $\left(-\mathrm{C}_{6} \mathrm{H}_{8} \mathrm{O}_{6}\right), 226.072^{+}\left(-\mathrm{CH}_{3}\right.$ from $\left.241.111^{+}\right), 198.074^{+}\left(-\mathrm{CO}\right.$ from $\left.226.072^{+}\right)$. The glucuronidation site was putatively assigned to $N^{2}$ since $N^{2}$ is a more favored site than $N 3$ when $N^{2}$ is not hydroxylated.

XVIN ${ }^{2}$-OH-PhIP- $N^{2}$-glucuronide (3.40 min): $417.143^{+}$(parent ion), $241.110^{+}$($\left.\mathrm{C}_{6} \mathrm{H}_{8} \mathrm{O}_{6}\right), 223.096^{+}\left(-\mathrm{H}_{2} \mathrm{O}\right.$ from $241.110^{+}$), ions $206.067^{+}$and $196.055^{+}$(from structural rearrangement).

XVIN $^{2}$-OH-PhIP-N3-glucuronide (4.47 min): $417.154^{+}$(parent ion), $241.110^{+}$($\mathrm{C}_{6} \mathrm{H}_{8} \mathrm{O}_{6}$ ), 225.117 (structural rearrangement to $\mathrm{PhIP},-\mathrm{O}$ from $241.110^{+}$), $224.102^{+}$(-OH from $241.110^{+}$). The RT of this metabolite was longer than $N^{2}-$ OHPhIP- $N^{2}$-glucuronide (XVI) as reported previously (13).

XVIM. $24^{\prime}$-diOH-PhIP glucuronide (2.25 min): $433.134^{+}$(parent), $257.114^{+}\left(-\mathrm{C}_{6} \mathrm{H}_{8} \mathrm{O}_{6}\right)$, $240.102_{+}\left(-\mathrm{OH}\right.$ from $\left.257.114^{+}\right), 239.093^{+}\left(-\mathrm{H}_{2} \mathrm{O}\right.$ from $\left.257.114^{+}\right)$.

On the basis of the above-mentioned structural information on PhIP metabolites, a comprehensive PhIP metabolism map was constructed (Figure 3). Total 17 PhIP metabolites were generated through individual reaction or the combination of oxidation and conjugation 
reactions, including $N^{2}-, 5-$, and 4'-hydroxylation; O-sulfation; $\mathrm{O}-, N^{2}-$, and $N 3-$ glucuronidation; and $N$-methylation.

\section{Relative Composition of Urinary PhIP Metabolites in Wild-Type, Cyp1a2-Null, and CYP1A2- Humanized Mice}

Discrete separation of PhIP-treated urine samples in a three-humanized mice as evidenced by the high abundance of $N^{2-}$ hydroxy metabolites (XVI, $N^{2}$-OH-PhIP- $N^{2}$-glucuronide; and XVII, $N^{2}$-OH-PhIP- $N 3$-glucuronide) and relatively low abundance of $4^{\prime}$-hydroxy metabolites (III,4'-OH-PhIP; VII,4'-OHPhIP sulfate; XIII, 4'-OH-PhIP glucuronide; and XV, 4'-OHPhIP$N^{2}$-glucuronide). Third, the absence of CYP1A2 in Cypla2- null mice diverted PhIP metabolism from oxidation reactions to conjugation reactions, causing dramatic increases of the $N$-methylation products (II, $N^{2}$-methyl-PhIP; and VI, $N^{2}$-methyl-4'-OH-PhIP) and a metabolite arising from direct glucuronidation (XII, PhIP- $N^{2}$-glucuronide), which also contributed to the separation of PhIP-treated Cypla2-null mice from other animal groups in the third principal component. However, it should be noted that $N^{2}$-OH-PhIP- $N 3$-glucuronide (XVII), a product of the $N^{2}$-hydroxylation reaction, still occurred as a major metabolite in Cypla2-null mice (although in less amount than wild-type and humanized mice), indicating that other P450 enzymes might also be involved in the metabolism of PhIP. Overall, the differences of urinary PhIP metabolites among three mouse lines, as reflected in Table 1, were consistent with the conclusion from PCA analysis as indicated in the scores scatter plot and loadings scatter plot (Figure 1A,B).

To examine the metabolism of PhIP at a dose more close to real-life human exposure, the quantities of urinary PhIP metabolites after oral administration of $100 \mu \mathrm{g} / \mathrm{kg}$ radiolabeled $\mathrm{PhIP}$ were measured. As shown in Figure 5, the metabolite profiles of radiolabeled PhIP in three mouse lines with high 4'-hydroxylation product (VII,4'-OH-PhIP sulfate) in wild-type mice, high parent $\mathrm{PhIP}$ compound (I) in Cypla2-null mice, and high $N^{2}$-hydroxylation products (XVI, $N^{2}$-OH-PhIP- $N^{2}$-glucuronide; and XVII, $N^{2}$-OH-PhIP-N3-glucuronide) in humanized mice were consistent with the results from metabolomic analysis. It should be noted that the discrepancy between the radioactivity assay and the LC-MS assay on the relative abundance of PhIP metabolites was largely due to dose-dependent metabolism $(10 \mathrm{mg} / \mathrm{kg}$ for LC-MS and $100 \mu \mathrm{g} / \mathrm{kg}$ for radio-HPLC) and the nonquantitative nature of the LC-MS method when authentic standards are absent.

Tissue DNA Adduction in Wild-Type, Cyp1a2-Null, and CYP1A2-Humanized Mice after PhIP Treatment

Because PhIP-induced DNA adduction was suggested as the initiation event of carcinogenesis, the levels of PhIP-DNA adducts in the liver, lung, colon, and mammary gland were examined after administration of radiolabeled PhIP (Figure 6). Results showed that humanized mice had a significantly higher level of PhIP-DNA adducts in examined tissues than wild-type and Cypla2- null mice $(P<0.01)$, which was consistent with the higher yield of bioactive $N^{2}$ hydroxy metabolites in humanized mice. However, with the exception of colon, the levels of PhIP-DNA in liver, lung, and mammary gland of wild-type mice were comparable with that of Cypla2-null mice. This observation further suggested that PhIP was still actively metabolized into genotoxic species through non-CYP1A2 bioactivation pathways in Cypla2null mice.

\section{Comparison of in Vitro Metabolism of PhIP by MLM from Wild-Type, Cyp1a2-Null Mice, and CYP1A2-Humanized Mice and by HLM}

To verify that the distinguished metabolite profiles of PhIP in the three mouse lines originated from metabolism in liver microsomes, PhIP was incubated with the MLMs from wild-type, Cypla2-null, and CYP1A2-humanized mice and pooled HLM, respectively. Consistent with 
the in vivo results, the 4'-hydroxylation activity of MLMs from Cyp 1a2-null and humanized mice was significantly reduced as compared to MLM from wild-type mice $(P<0.01)$, and MLM from humanized mice possessed a much higher $N^{2}$-hydroxylation activity than did wildtype $(P<0.01)$ (Figure 7$)$. While overall enzymatic activity of HLM was significantly lower than MLM from humanized mice $(P<0.01)$, the ratio of $4^{\prime}-\mathrm{OHPhIP}$ vs $N^{2}-\mathrm{OH}-\mathrm{PhIP}$ was comparable between these two microsomal preparations (Figure 7), indicating that CYP1A2humanized MLM can mimic HLM in the metabolism of PhIP. Furthermore, MLM from Cypla2-null mice still retained about 20\% 4'-hydroxylation and 30\% $N^{2}$-hydroxylation activities of wild-type mice.

\section{Potential Role of CYP2C Enzymes in the PhIP Metabolism}

Although both metabolite profiling and DNA adduct assays confirmed the importance of CYP1A2 in PhIP metabolism, significant $N^{2}$-hydroxylation of PhIP and extensive formation of DNA adduct were still observed in Cypla2-null mice, which implied the potential involvement of other P450s in the bioactivation of PhIP (Table 1 and Figure 6). Therefore, PhIP was incubated with a panel of recombinant human P450s, specifically CYP1A1, CYP1A2, CYP1B1, CYP2A6, CYP2B6, CYP2C8, CYP2C9, CYP2C18, CYP2C19, CYP2D6, CYP2E1, and CYP3A4. Results from the P450 panel incubation showed that, besides CYP1A2, the isozymes CYP1A1, CYP1B1, CYP2C19, and CYP2D6 can also function as PhIP-4'hydroxylases and CYP1A1, CYP1B1, and CYP2C19 can function as PhIP- $N^{2}$-hydroxylases (Figure 8A,B). Because of the insignificant hepatic levels of CYP1A1 and CYP1B1 enzymes (26) and the inability of CYP2D6 to form bioactive $N^{2}-\mathrm{OH}-\mathrm{PhIP}$, subsequent studies were focused on the potential role of CYP2C enzymes in the PhIP metabolism. First, enzyme kinetics of human CYP1A2 and CYP2C19 enzymes were compared. As indicated in Figure 8C,D, the enzymatic efficiency $\left(V_{\max } / K_{\mathrm{m}}\right)$ of CYP1A2 was about 3 - and 13 -fold that of CYP2C19 in the formation of 4-OH-PhIP and $N^{2}-\mathrm{OH}-\mathrm{PhIP}$, respectively. Therefore, it is probable that in comparison to human CYP1A2, CYP2C19 may only function as a minor enzyme in the metabolism of PhIP in human liver. Second, 4'-hydroxylase and $N^{2}$-hydroxylase activities of recombinant rat CYP1A2 and CYP2C11 enzymes were compared. As shown in Figure 9A, rat CYP2C11 differed from human CYP2C19 due to its inability to convert PhIP to 4'-OH-PhIP but nevertheless retained catalytic activity for generating $N^{2}$-OH-PhIP, which was largely consistent with a previous report (27). Although this result may not represent the $\mathrm{PhIP}$ metabolism activity of other rodent CYP2C enzymes, the observed $N^{2}$-hydroxylase activity of rat CYP2C11 implied that certain mouse CYP2C enzymes may also possess this activity. To examine this hypothesis, antibody inhibition assays were conducted to determine the relative contribution of mouse CYP1A2 and CYP2C enzymes to the formation of 4'-OH-PhIP and $N^{2}$-OH-PhIP. For the MLM from wild-type mice, as shown in Figure 9B, anti-mCYP1A2 mAb (1-7-1) blocked about $60 \%$ of both 4 '-hydroxylase and $N^{2}$-hydroxylase activities whereas the anti-rCYP2C11 mAb (1-68-11) could only reduce $N^{2}$-hydroxylase activity when used together with CYP1A2 antibody $(P<0.01$, as compared to mCYP1A2 antibody alone). However, when applied to the MLM from Cyp 1 a2-null mice, anti-rCYP2C11 mAb dramatically inhibited both 4'-hydroxylase and $N^{2}$-hydroxylase activities (Figure 9C), which indicated that mouse CYP2C enzymes may be the major PhIP metabolizing enzymes in the MLM of Cypla2-null mice.

\section{Discussion}

As a potent rodent carcinogen and one of the major food derived heterocyclic aromatic amines in the human diet, in vivo and in vitro biotransformation of PhIP have been extensively investigated. At least nine metabolites (III, IV, V, VII, XI, XII, XIII, XVI, and XVII) were identified from these studies (9). In this report, through the combination of high-resolution LCMS technology and comprehensive MDA on a relatively small sample size (four mice per genotype), eight novel metabolites (II, VI, VIII, IX, X, XIV, XV, and XVIII), some of which 
were present in urine in significant quantities, were identified and further structurally elucidated by $\mathrm{MS}^{2}$ fragmentation analysis. This result, in accordance with recent studies on the metabolism of arecoline (a bioactive alkaloid from areca nut) (28) and aminoflavone (a novel anticancer agent) (29), underscores the value of LC-MS-based metabolomic approach as a powerful tool for drug metabolism and chemical toxicology research (18). As compared to traditional radioactivity tracing methods, MDA-based metabolite profilings have a clear advantage for not being dependent on the preparation of radiolabeled parent compounds, which can be costly and time-consuming. By measuring exact masses of metabolites, a highresolution LC-MS technical platform provides an excellent starting point for structural elucidation of novel metabolites. Furthermore, because the existence of parent compound and its metabolites in control and treated samples is a "none-andall" situation, by applying appropriate data-scaling techniques, the variables representing major metabolites in the multivariate model can be easily identified by an unsupervised PCA or a supervised partial least-squares-discriminant analysis (PLS-DA) based on their heavy contribution to the principal components and to the separation of control and treated samples, as evidenced by this PhIP study (Figure 1). For the same reason, this strategy does not discriminate metabolites from uncommon metabolism reactions against metabolites from common reactions as the mass defect filtering (MDF) methods did through examining the differences between the measured masses and the expected masses of metabolites generated by common metabolic reactions $(30,31)$. Therefore, when combined with accurate mass measurement and software-assisted metabolite screening, metabolomic analysis can potentially lead to the exhaustive detection of major and minor metabolites, whether they originated from common or uncommon metabolic reactions. By using this strategy, a novel $N$-methylation reaction of PhIP was identified in this study. Another interesting observation from this study was the relative low variance of the data on the relative composition of urinary PhIP metabolites (Table 1) in contrast to the high variance of the absolute quantitation of individual metabolites in urine (data not shown). This significant decrease of data variance was mainly attributed to the reduction of exogenous influence from urine volume, diet and fecal contaminations, and other factors by calculating the relative percentage of each metabolite in the whole metabolite cluster. Furthermore, the results from this study provided convincing evidence to support the application of metabolomic analysis as an efficient tool to examine the influence of genetic modification and drug-drug interaction on drug metabolism.

Although urinary levels of $N^{2}-\mathrm{OH}-\mathrm{PhIP}$ in wild-type, Cypla2- null, and CYP1A2- humanized mice were previously compared (19), comprehensive profiles of PhIP metabolism in these three mouse lines have not been reported. Results from metabolomic analysis and radiolabeled metabolite analysis in this study provided a detailed view on the distribution of each PhIP metabolite and its potential biotransformation pathway and further confirmed the importance of CYP1A2 in PhIP metabolism and the interspecies difference between human and rodent, which were consistent with conclusions from previous in vitro studies $(9,14)$. Interestingly, the clear dominance of CYP1A2 in PhIP metabolism did not correlate well with the results of DNA adduct assays that showed that wild-type and Cyp1a2-null mice had comparable levels of PhIP-DNA adducts in liver, lung, and mammary gland, although this latter observation was consistent with the result from a recent study showing comparable tumorigenesis in wild-type and Cypla2-null mice after PhIP treatment (15). To obtain more insight into this issue, several in vitro incubation experiments were conducted to examine the possible involvement of other P450s. Subsequently, human CYP2C19 was identified as another PhIP metabolizing enzyme, even though its enzymatic efficiency $\left(V_{\max } / K_{\mathrm{m}}\right)$ was much lower than CYP1A2. The potential role of CYP2C enzymes in murine PhIP metabolism, especially in Cypla2-null mice, was further examined by antibody inhibition, in which anti-rCYP2C11 mAb abolished about $80 \%$ $N^{2}$-hydroxylase activity of MLM from Cypla2-null mice. It should be noted that, as compared to the well-characterized human CYP2C subfamily, which is mainly comprised of CYP2C8, $2 \mathrm{C} 9,2 \mathrm{C} 18$, and $2 \mathrm{C} 19$, the mouse $\mathrm{CYP} 2 \mathrm{C}$ subfamily contains at least 15 genes and four pseudo- 
genes (32), and catalytic functions of many mouse CYP2C enzymes are still largely unknown. In addition, the expression levels of mouse CYP2Cs is quite high in many extrahepatic tissues $(33,34)$, which implies that mouse CYP2C enzymes may have a more important role in xenobiotic metabolism than their human counterparts. Therefore, the role of CYP2C enzymes in PhIP metabolism can be tentatively defined as follows: First, in human, in comparison to CYP1A2, the contribution of CYP2C19 to PhIP metabolism is probably minimal for its low catalytic activity and low expression level in extrahepatic tissues. Second, in mouse, the contribution of CYP2C enzymes to hepatic PhIP metabolism may still be minor, based on the result of antibody inhibition of MLM from wild-type mice. However, their role in the extrahepatic metabolism of PhIP could be significant due to their abundance in those tissues. Further studies are required to validate this hypothesis.

Third, in Cypla2-null mice, CYP2C enzymes are the major enzymes responsible for the PhIPmetabolizing activity in liver. Because of the structural similarity among HCA compounds, to which PhIP belongs, all of the potential roles of CYP2C enzymes in the PhIP metabolism may also be well applicable to other HCAs, such as IQ and MeIQx. This hypothesis is supported by a recent study on the metabolism of aminoflavone (structurally related to HCAs), in which the potential role of CYP2C enzymes was also identified(29). With regard to the comparable levels of PhIP-DNA adducts and tumor incidence (15) in wild-type and Cypla2-null mice, similar studies on 4-aminobiphenyl, another HCA carcinogen, also showed that DNA adduction and chemical carcinogenesis were not reduced in Cypla2-null mice $(35,36)$. A possible explanation is that without the CYP1A2-mediated hepatic metabolism, more unchanged parent compound, as evidenced by the high amount of PhIP in Cypla2-null urine, can enter the circulation and move to nonliver tissues for further local metabolism, potentially by CYP2C enzymes or CYP1A1 as indicated by a recent study on the PhIP metabolism in lung (37). Therefore, significant or even higher extrahepatic metabolism of PhIP is expected in Cypla2-null mice than in wild-type mice. Future studies will provide more insight into this issue.

The use of genetically modified P450 animal models, including gene knockout and transgenic mice, provides a powerful tool for studying xenobiotics metabolism. Because of the important role of CYP1A2 enzyme in drug metabolism and chemical carcinogenesis, both Cypla2-null and CYP1A2- humanized mouse models have beneficial values for studying the metabolism of CYP1A2 substrates as well as interspecies differences between human and mouse $(19,38)$. Similarly, animal models on CYP1A1 (39), CYP1B1 (40), CYP2E1 (41), and CYP3A4 (42) have been proven to be useful tools for determining the role of P450s in the metabolism of xenobiotics and endogenous chemicals and the modulation of normal homeostasis and for understanding the mechanism of chemical carcinogenesis (43).

In summary, by combining high-resolution LC-MS technology and MDA used in metabolomics, 17 urinary PhIP metabolites including eight novel metabolites, from P450dependent or independent oxidation as well as glucuronidation, sulfation, and methylation reactions, were identified and structurally elucidated, and a comprehensive in vivo metabolic pathway of PhIP was constructed (Figure 3). Significant differences in the relative composition of urinary metabolites among three mouse lines demonstrated that CYP1A2, especially human CYP1A2, plays an important role in the PhIP metabolism and bioactivation although it may not be the only enzyme capable of oxidizing PhIP. In vitro incubations of PhIP with microsomes and recombinant P450s, as well as enzyme kinetics and antibody inhibition assays, confirmed this conclusion and further indicated that CYP2C enzymes might also contribute to PhIP metabolism. 


\section{Supplementary Material}

Refer to Web version on PubMed Central for supplementary material.

\section{Acknowledgements}

We thank NCI Chemical Carcinogen Reference Standard Repository for providing $N^{2}$-OH-PhIP standard and Dr. Minako Nagao of the Japan National Cancer Center Research Institute for 4'-OH-PhIP standard. This study was supported by the NCI Intramural Research Program of the NIH. This work was also partially performed under the auspices of the U.S. Department of Energy by the University of California, Lawrence Livermore National Laboratory, at the Research Resource for Biomedical AMS under Contract W-7405-Eng-48 and supported by National Cancer Institute Grants CA55861 and RR13461. J.R.I. is grateful to the U.S. Smokeless Tobacco Company for a grant for collaborative research.

\section{References}

(1). Felton, JS.; Jagerstad, M.; Knize, MG.; Skog, K.; Wakabayashi, K. Contents in foods, beverages and tobacco. In: Nagao, M.; Sugimura, T., editors. Food Borne Carcinogens. John Wiley \& Sons; New York: 2000. p. 31-72.

(2). Ushiyama H, Wakabayashi K, Hirose M, Itoh H, Sugimura T, Nagao M. Presence of carcinogenic heterocyclic amines in urine of healthy volunteers eating normal diet, but not of inpatients receiving parenteral alimentation. Carcinogenesis 1991;12:1417-1422. [PubMed: 1907222]

(3). Peluso M, Castegnaro M, Malaveille C, Friesen M, Garren L, Hautefeuille A, Vineis P, Kadlubar F, Bartsch H. 32P Postlabelling analysis of urinary mutagens from smokers of black tobacco implicates 2-amino-1-methyl-6-phenylimidazo[4,5-b]pyridine (PhIP) as a major DNA-damaging agent. Carcinogenesis 1991;12:713-717. [PubMed: 2013135]

(4). Esumi H, Ohgaki H, Kohzen E, Takayama S, Sugimura T. Induction of lymphoma in CDF1 mice by the food mutagen, 2-amino-1-methyl-6-phenylimidazo[4,5-b]pyridine. Jpn. J. Cancer Res 1989;80:1176-1178. [PubMed: 2516847]

(5). Ito N, Hasegawa R, Imaida K, Tamano S, Hagiwara A, Hirose M, Shirai T. Carcinogenicity of 2amino-1-methyl-6-phenylimidazo[4,5-b]pyridine (PhIP) in the rat. Mutat. Res 1997;376:107-114. [PubMed: 9202745]

(6). Frandsen H, Alexander J. N-acetyltransferase-dependent activation of 2-hydroxyamino-1-methyl-6phenylimidazo[4,5-b]pyri-dine: Formation of 2-amino-1-methyl-6-(5-hydroxy)phenylimidazo [4,5-b]pyridine, a possible biomarker for the reactive dose of 2-amino-1-methyl-6-phenylimidazo [4,5-b]pyridine. Carcinogenesis 2000;21:1197-1203. [PubMed: 10837010]

(7). Turesky RJ. Heterocyclic aromatic amine metabolism, DNA adduct formation, mutagenesis, and carcinogenesis. Drug Metab. Rev 2002;34:625-650. [PubMed: 12214671]

(8). Snyderwine EG, Turesky RJ, Turteltaub KW, Davis CD, Sadrieh N, Schut HA, Nagao M, Sugimura T, Thorgeirsson UP, Adamson RH, Thorgeirsson SS. Metabolism of food-derived heterocyclic amines in nonhuman primates. Mutat. Res 1997;376:203-210. [PubMed: 9202757]

(9). Langouet S, Paehler A, Welti DH, Kerriguy N, Guillouzo A, Turesky RJ. Differential metabolism of 2-amino-1-methyl-6-phenylimidazo[4,5-b]pyridine in rat and human hepatocytes. Carcinogenesis 2002;23:115-122. [PubMed: 11756232]

(10). Reistad R, Frandsen H, Grivas S, Alexander J. In vitro formation and degradation of 2-amino-1methyl-6-phenylimidazo[4,5-b]pyridine (PhIP) protein adducts. Carcinogenesis 1994;15:25472552. [PubMed: 7955104]

(11). Frandsen H, Frederiksen H, Alexander J. 2-Amino-1-methyl-6-(5-hydroxy-)phenylimidazo[4,5-b] pyridine (5-OH-PhIP), a biomarker for the genotoxic dose of the heterocyclic amine, 2-amino-1methyl-6-phenylimidazo[4,5-b]pyridine (PhIP). Food Chem. Toxicol 2002;40:1125-1130. [PubMed: 12067574]

(12). Malfatti MA, Ubick EA, Felton JS. The impact of glucuronidation on the bioactivation and DNA adduction of the cooked-food carcinogen 2-amino-1-methyl-6-phenylimidazo[4,5-b]-pyridine in vivo. Carcinogenesis 2005;26:2019-2028. [PubMed: 15944213] 
(13). Kaderlik KR, Mulder GJ, Turesky RJ, Lang NP, Teitel CH, Chiarelli MP, Kadlubar FF. Glucuronidation of N-hydroxy heterocyclic amines by human and rat liver microsomes. Carcinogenesis 1994;15:1695-1701. [PubMed: 8055651]

(14). Turesky RJ, Constable A, Fay LB, Guengerich FP. Interspecies differences in metabolism of heterocyclic aromatic amines by rat and human P450 1A2. Cancer Lett 1999;143:109-112. [PubMed: 10503887]

(15). Kimura S, Kawabe M, Yu A, Morishima H, Fernandez-Salguero P, Hammons GJ, Ward JM, Kadlubar FF, Gonzalez FJ. Carcinogenesis of the food mutagen PhIP in mice is independent of CYP1A2. Carcinogenesis 2003;24:583-587. [PubMed: 12663521]

(16). Griffin JL. The Cinderella story of metabolic profiling: Does metabolomics get to go to the functional genomics ball? Philos. Trans. R. Soc. London, Ser. B 2006;361:147-161. [PubMed: 16553314]

(17). Nicholson JK, Lindon JC, Holmes E. 'Metabonomics': Understanding the metabolic responses of living systems to pathophysiological stimuli via multivariate statistical analysis of biological NMR spectroscopic data. Xenobiotica 1999;29:1181-1189. [PubMed: 10598751]

(18). Plumb RS, Stumpf CL, Granger JH, Castro-Perez J, Haselden JN, Dear GJ. Use of liquid chromatography/time-of-flight mass spectrometry and multivariate statistical analysis shows promise for the detection of drug metabolites in biological fluids. Rapid Commun. Mass Spectrom 2003;17:2632-2638. [PubMed: 14648901]

(19). Cheung C, Ma X, Krausz KW, Kimura S, Feigenbaum L, Dalton TP, Nebert DW, Idle JR, Gonzalez FJ. Differential metabolism of 2-amino-1-methyl-6-phenylimidazo[4,5-b]pyridine (PhIP) in mice humanized for CYP1A1 and CYP1A2. Chem. Res. Toxicol 2005;18:1471-1478. [PubMed: 16167840]

(20). Pineau T, Fernandez-Salguero P, Lee SS, McPhail T, Ward JM, Gonzalez FJ. Neonatal lethality associated with respiratory distress in mice lacking cytochrome P450 1A2. Proc. Natl. Acad. Sci. U.S.A 1995;92:5134-5138. [PubMed: 7761462]

(21). Yu AM, Idle JR, Krausz KW, Kupfer A, Gonzalez FJ. Contribution of individual cytochrome P450 isozymes to the $\mathrm{O}$-demethylation of the psychotropic beta-carboline alkaloids harmaline and harmine. J. Pharmacol. Exp. Ther 2003;305:315-322. [PubMed: 12649384]

(22). Park SS, Fujino T, West D, Guengerich FP, Gelboin HV. Monoclonal antibodies that inhibit enzyme activity of 3-methylcholanthrene-induced cytochrome P-450. Cancer Res 1982;42:1798-1808. [PubMed: 6175397]

(23). Park SS, Waxman DJ, Lapenson DP, Schenkman JB, Gelboin HV. Monoclonal antibodies to rat liver cytochrome P-450 2c/RLM5 that regiospecifically inhibit steroid metabolism. Biochem. Pharmacol 1989;38:3067-3074. [PubMed: 2783161]

(24). Malfatti MA, Felton JS. N-glucuronidation of 2-amino-1-methyl-6-phenylimidazo[4,5-b]pyridine (PhIP) and N_hydroxy-PhIP by specific human UDP-glucuronosyltransferases. Carcinogenesis 2001;22:1087-1093. [PubMed: 11408353]

(25). Styczynski PB, Blackmon RC, Groopman JD, Kensler TW. The direct glucuronidation of 2amino-1-methyl-6-phenylimidazo[4,5-b] pyridine (PhIP) by human and rabbit liver microsomes. Chem. Res. Toxicol 1993;6:846-851. [PubMed: 8117924]

(26). Guengerich, FP. Human cytochrome P450 enzymes. In: Montellano, P. R. O. d., editor. Cytochrome P450-Structure, Mechanism, and Biochemistry. Kluwer Academic/Plenum Publishers; New York: 2005. p. 377-463.

(27). Wallin H, Mikalsen A, Guengerich FP, Ingelman-Sundberg M, Solberg KE, Rossland OJ, Alexander J. Differential rates of metabolic activation and detoxication of the food mutagen 2-amino-1methyl-6-phenylimidazo[4,5-b]pyridine by different cyto-chrome P450 enzymes. Carcinogenesis 1990;11:489-492. [PubMed: 2311193]

(28). Giri S, Idle JR, Chen C, Zabriskie TM, Krausz KW, Gonzalez FJ. A metabolomic approach to the metabolism of the areca nut alkaloids arecoline and arecaidine in the mouse. Chem. Res. Toxicol 2006;19:818-827. [PubMed: 16780361]

(29). Chen C, Meng L, Ma X, Krausz KW, Pommier Y, Idle JR, Gonzalez FJ. Urinary metabolite profiling reveals CYP1A2-mediated metabolism of NSC686288 (aminoflavone). J. Pharmacol. Exp. Ther 2006;318:1330-1342. [PubMed: 16775196] 
(30). Mortishire-Smith RJ, O'Connor D, Castro-Perez JM, Kirby J. Accelerated throughput metabolic route screening in early drug discovery using high-resolution liquid chromatography/quadrupole time-of-flight mass spectrometry and automated data analysis. Rapid Commun. Mass Spectrom 2005;19:2659-2670. [PubMed: 16124034]

(31). Zhu M, Ma L, Zhang D, Ray K, Zhao W, Humphreys WG, Skiles G, Sanders M, Zhang H. Detection and characterization of metabolites in biological matrices using mass defect filtering of liquid chromatography/high resolution mass spectrometry data. Drug Metab. Dispos 2006;34:1722-1733. [PubMed: 16815965]

(32). Nelson DR, Zeldin DC, Hoffman SM, Maltais LJ, Wain HM, Nebert DW. Comparison of cytochrome P450 (CYP) genes from the mouse and human genomes, including nomenclature recommendations for genes, pseudogenes and alternative-splice variants. Pharmacogenetics 2004;14:1-18. [PubMed: 15128046]

(33). Tsao CC, Coulter SJ, Chien A, Luo G, Clayton NP, Maronpot R, Goldstein JA, Zeldin DC. Identification and localization of five CYP2Cs in murine extrahepatic tissues and their metabolism of arachidonic acid to regio- and stereoselective products. J. Pharmacol. Exp. Ther 2001;299:3947. [PubMed: 11561061]

(34). Wang H, Zhao Y, Bradbury JA, Graves JP, Foley J, Blaisdell JA, Goldstein JA, Zeldin DC. Cloning, expression, and characterization of three new mouse cytochrome p450 enzymes and partial characterization of their fatty acid oxidation activities. Mol. Pharmacol 2004;65:1148-1158. [PubMed: 15102943]

(35). Tsuneoka Y, Dalton TP, Miller ML, Clay CD, Shertzer HG, Talaska G, Medvedovic M, Nebert DW. 4-aminobiphenyl-induced liver and urinary bladder DNA adduct formation in Cyp1a2(-/-) and Cyp1a2(+/+) mice. J. Natl. Cancer Inst 2003;95:1227-1237. [PubMed: 12928348]

(36). Kimura S, Kawabe M, Ward JM, Morishima H, Kadlubar FF, Hammons GJ, Fernandez-Salguero $\mathrm{P}$, Gonzalez FJ. CYP1A2 is not the primary enzyme responsible for 4-aminobiphenyl-induced hepatocarcinogenesis in mice. Carcinogenesis 1999;20:1825-1830. [PubMed: 10469630]

(37). Ma X, Idle JR, Malfatti MA, Krausz KW, Nebert DW, Chen CS, Felton JS, Waxman DJ, Gonzalez FJ. Mouse lung CYP1A1 catalyzes the metabolic activation of 2-amino-1-methyl-6-phenylimidazo [4,5-b]pyridine (PhIP). Carcinogenesis. Accepted for publication.

(38). Buters JT, Tang BK, Pineau T, Gelboin HV, Kimura S, Gonzalez FJ. Role of CYP1A2 in caffeine pharmacokinetics and metabolism: Studies using mice deficient in CYP1A2. Pharmacogenetics 1996;6:291-296. [PubMed: 8873215]

(39). Uno S, Dalton TP, Dragin N, Curran CP, Derkenne S, Miller ML, Shertzer HG, Gonzalez FJ, Nebert DW. Oral benzo[a]pyrene in Cyp1 knockout mouse lines: CYP1A1 important in detoxication, CYP1B1 metabolism required for immune damage independent of total-body burden and clearance rate. Mol. Pharmacol 2006;69:1103-1114. [PubMed: 16377763]

(40). Buters JT, Sakai S, Richter T, Pineau T, Alexander DL, Savas U, Doehmer J, Ward JM, Jefcoate CR, Gonzalez FJ. Cytochrome P450 CYP1B1 determines susceptibility to 7,12-dimethylbenz[a] anthracene-induced lymphomas. Proc. Natl. Acad. Sci. U.S.A 1999;96:1977-1982. [PubMed: 10051580]

(41). Cheung C, Yu AM, Ward JM, Krausz KW, Akiyama TE, Feigenbaum L, Gonzalez FJ. The cyp2e1humanized transgenic mouse: role of cyp2e1 in acetaminophen hepatotoxicity. Drug Metab. Dispos 2005;33:449-457. [PubMed: 15576447]

(42). Granvil CP, Yu AM, Elizondo G, Akiyama TE, Cheung C, Feigenbaum L, Krausz KW, Gonzalez FJ. Expression of the human CYP3A4 gene in the small intestine of transgenic mice: In vitro metabolism and pharmacokinetics of midazolam. Drug Metab. Dispos 2003;31:548-558. [PubMed: 12695342]

(43). Gonzalez FJ. Role of gene knockout and transgenic mice in the study of xenobiotic metabolism. Drug Metab. Rev 2003;35:319-335. [PubMed: 14705864] 

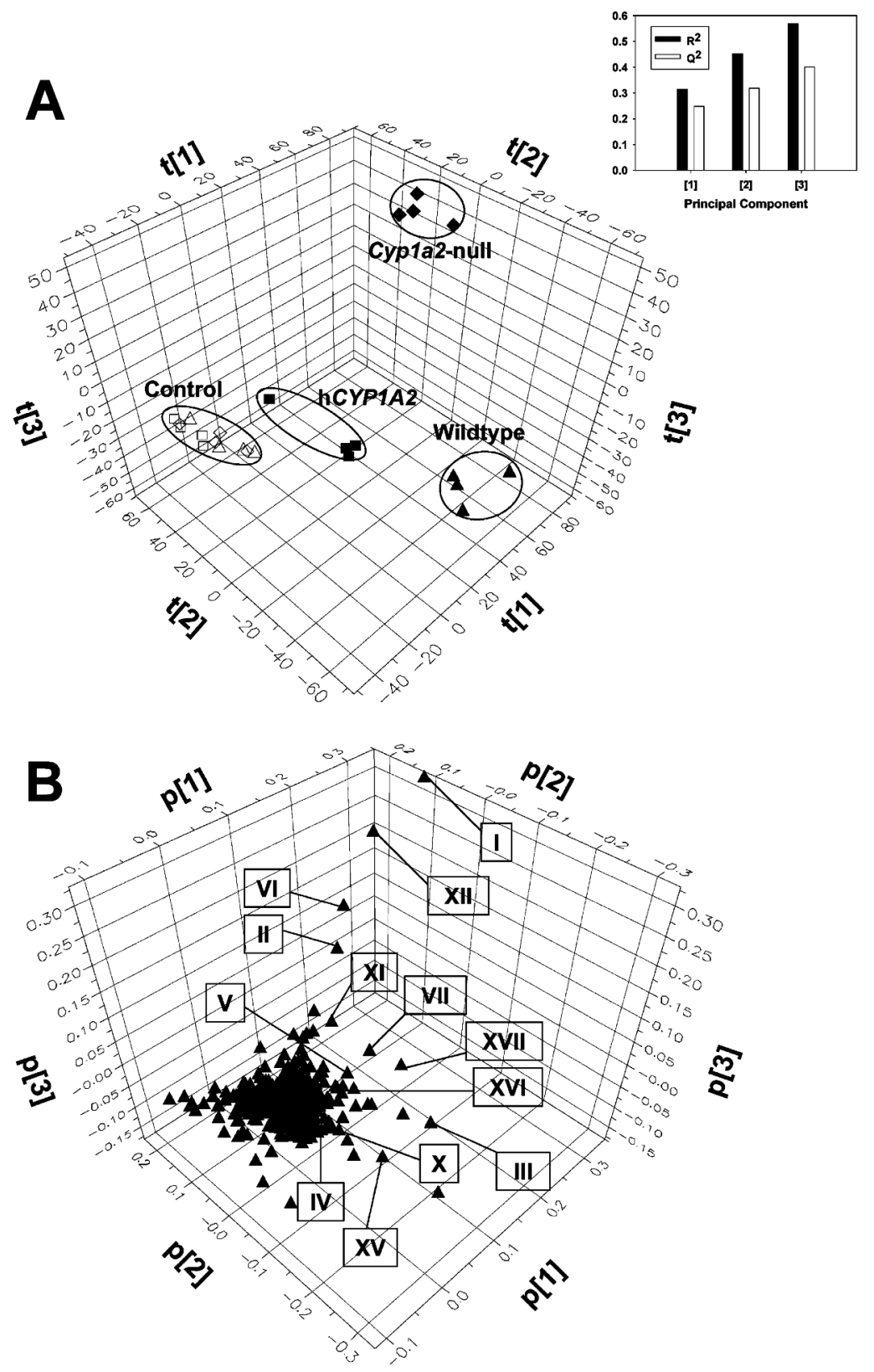

Figure 1.

PCA on urine metabolomes of control and PhIP-treated wild-type, Cypla2-null, and CYP1A2- humanized mice. Data acquisition and analysis are described in the Experimental Procedures. (A) Scores scatter plot of PCA model on $24 \mathrm{~h}$ urine samples from the control (wildtype, $\triangle$; Cypla2-null, $\diamond$; and CYP1A2-humanized, $\square$ ) and PhIP-treated (wild-type, $\mathbf{\Delta}$; Cypla2-null, and CYP1A2- humanized, a) mice. The $t[1], t[2]$, and $t[3]$ values represent the scores of each sample in principle components 1,2 , and 3 , respectively. Fitness and prediction power of three components in the model are represented as $R^{2}$ and $Q^{2}$ values in the inset chart (upper right), respectively. (B) Loadings scatter plot of all detected urinary ions in the PCA model. The $p[1], p[2]$, and $p$ [3] values represent the contributing weights of each ion to principal components 1,2 , and 3 , respectively. 

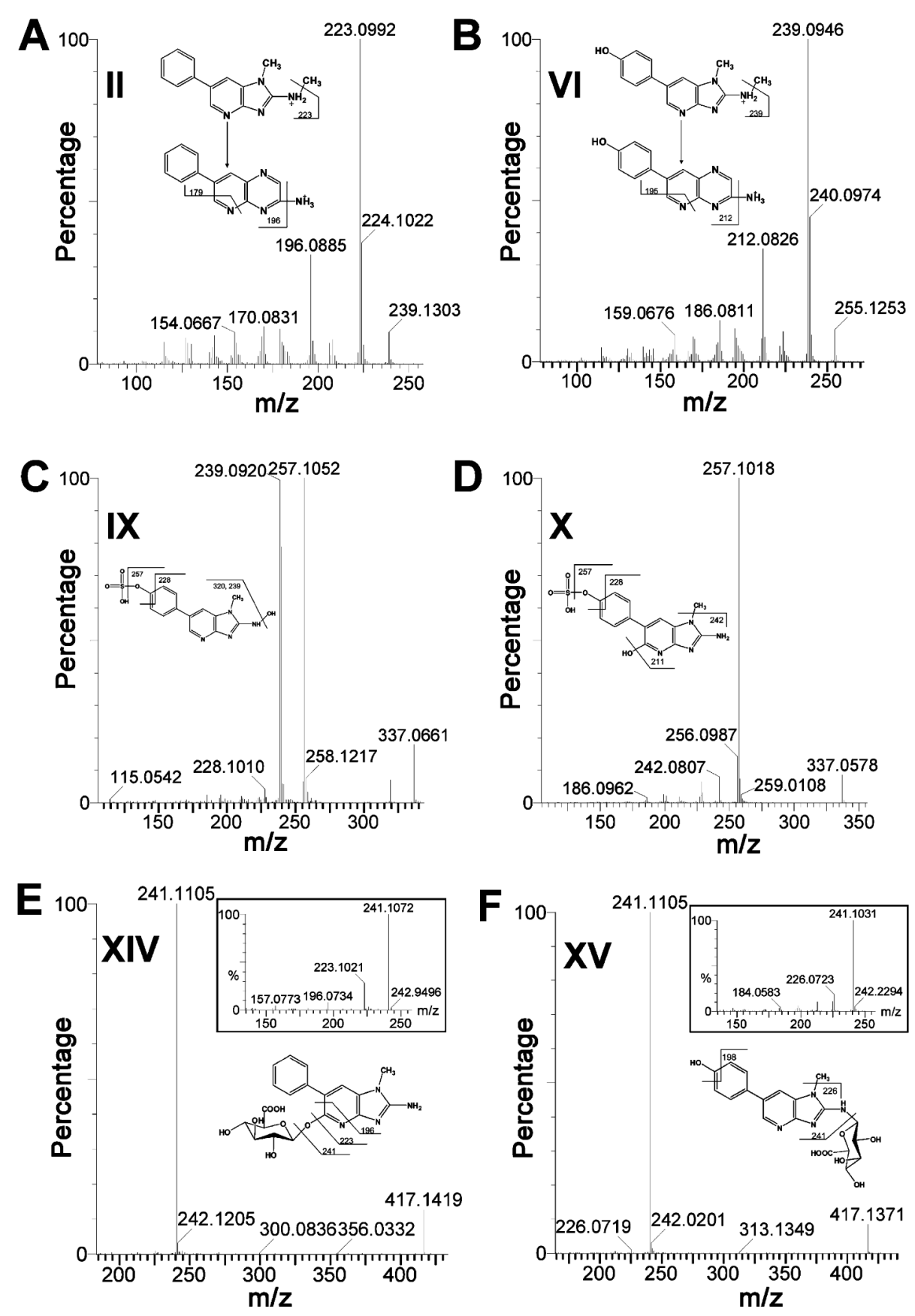

Figure 2.

LC-MS/MS structural elucidation of urinary PhIP metabolites. Conditions for LC-MS/MS were described in the Experimental Procedures. $\mathrm{MS}^{2}$ fragmentation was conducted with collision energy ramping from 15 to $35 \mathrm{eV}$. (A) $\mathrm{MS}^{2}$ fragmentation of $N^{2}$-methyl-PhIP (II). (B) $\mathrm{MS}^{2}$ fragmentation of $N^{2}$-methyl-PhIP-4'-OH-PhIP (VI). (C) MS ${ }^{2}$ fragmentation of $N^{2}, 4^{\prime}$ diOH-PhIP sulfate (IX). (D) MS ${ }^{2}$ fragmentation of 5,4'-diOHPhIP sulfate (X). (E) MS ${ }^{2}$ fragmentation of 5-OH-PhIP glucuronide (XIV) with inlaid spectrum of deconjugated 5-OHPhIP ion. (F) MS ${ }^{2}$ fragmentation of 4'-OH-PhIP- $N^{2}$-glucuronide (XV) with inlaid spectrum of deconjugated 4'-OH-PhIP ion. Major daughter ions from fragmentation were interpreted in the inlaid structural diagrams. 


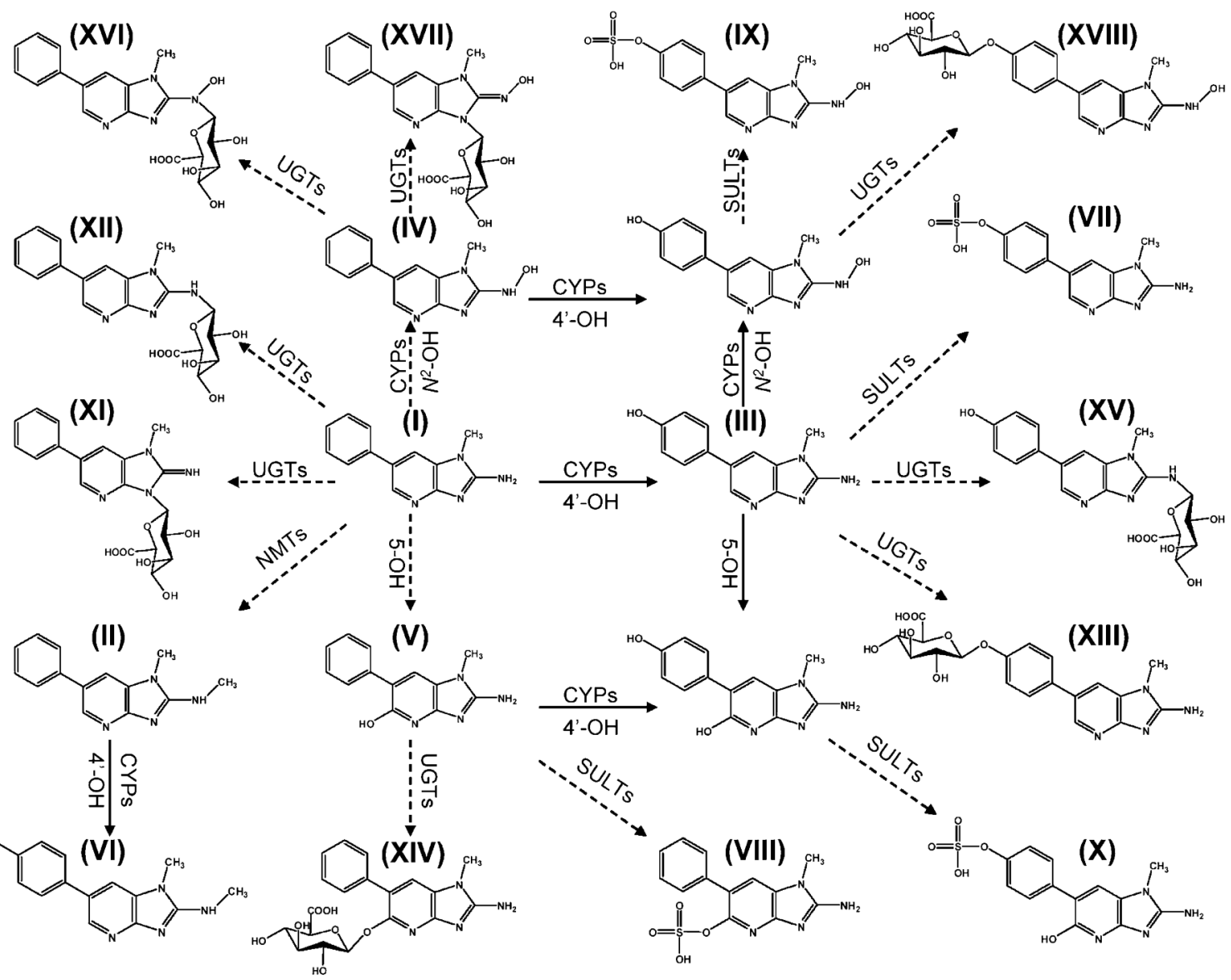

Figure 3.

Major in vivo PhIP metabolism pathways. Both oxidation and conjugation metabolizing enzymes convert $\mathrm{PhIP}(\mathbf{I})$, collectively or separately, into 17 structurally diversified metabolites. CYP-dependent or -independent oxidation reactions at $N^{2}, C^{5}$, and $C^{4^{\prime}}$ positions transform PhIP to three monohydroxylated metabolites (III-V), which can be further metabolized to two dihydroxylated metabolites. Besides catalyzing direct $N$-conjugation of $\mathrm{PhIP}$ (I) to metabolites XI and XII, UDP-glucuronosyltransferases (UGTs) can also convert oxidized metabolites into glucuronides (XIII, XIV, XV, XVI, XVII, and XVIII). Cytosolic sulfotransferases (SULTs) can metabolize oxidized metabolites to sulfates (VII, VIII, IX, and $\mathbf{X}$ ), and $N$-methyltransferases (NMTs) can form more hydrophobic metabolite II, which can be further metabolized to metabolite VI. Solid lines represent oxidation reactions, and dashed lines represent conjugation reactions. 


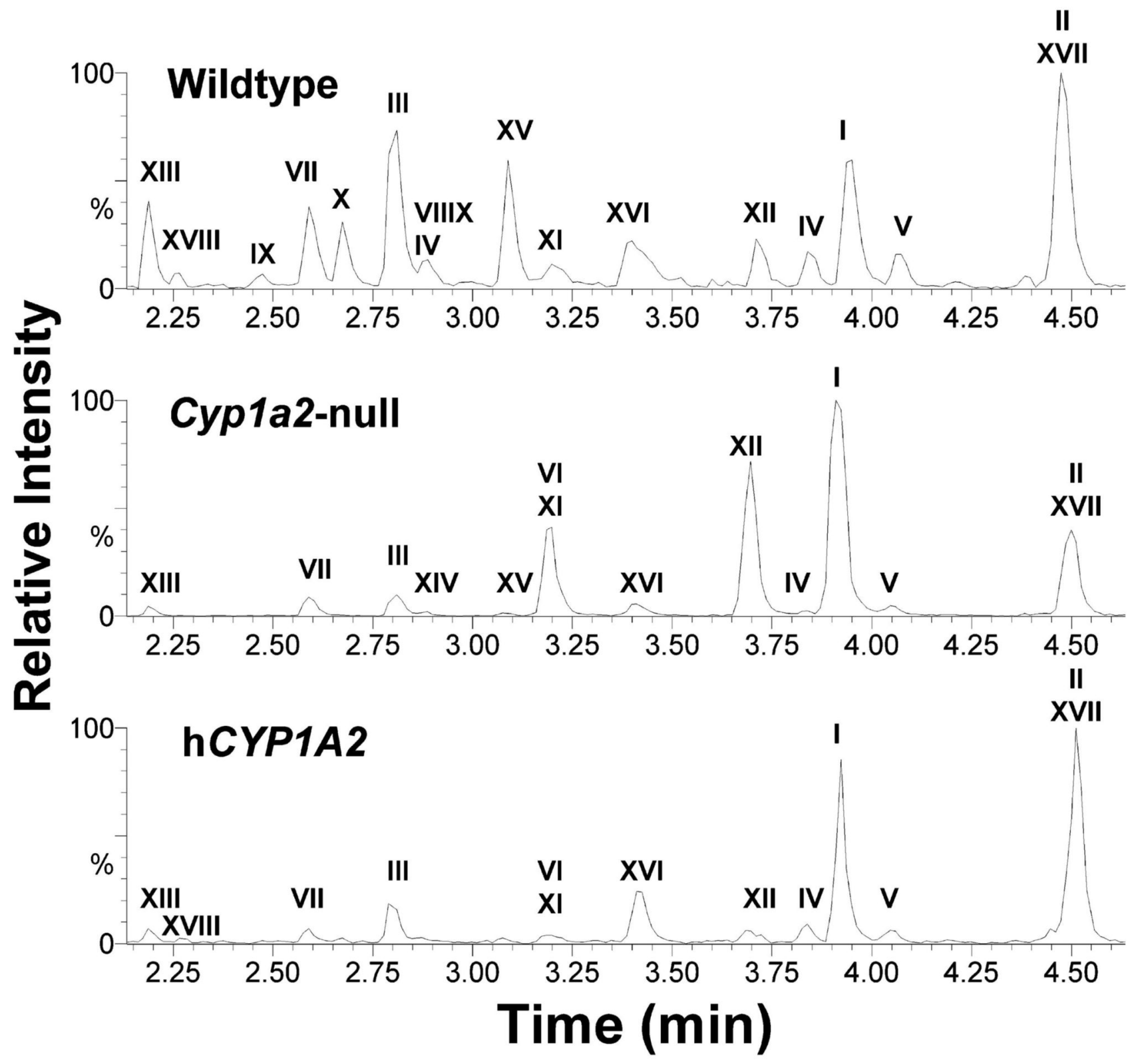

Figure 4.

Representative chromatograms of major PhIP metabolites in urine samples of wild-type, Cypla2-null, and CYP1A2- humanized mice. Ions within the $20 \mathrm{ppm}$ range of theoretical accurate mass $\left([\mathrm{M}+\mathrm{H}]^{+}\right)$of PhIP and its metabolites (225.1140, 239.1283, 241.1089, 255.1246, 257.1039, 321.0658, 337.0607, 401.1461, 417.1410, and 433.1359) were extracted from each $10 \mathrm{~min}$ LC-MS run. The ion intensity of the most abundant metabolites was set arbitrarily as $100 \%$. The identities and relative abundances of labeled metabolites were presented in Table 1. 


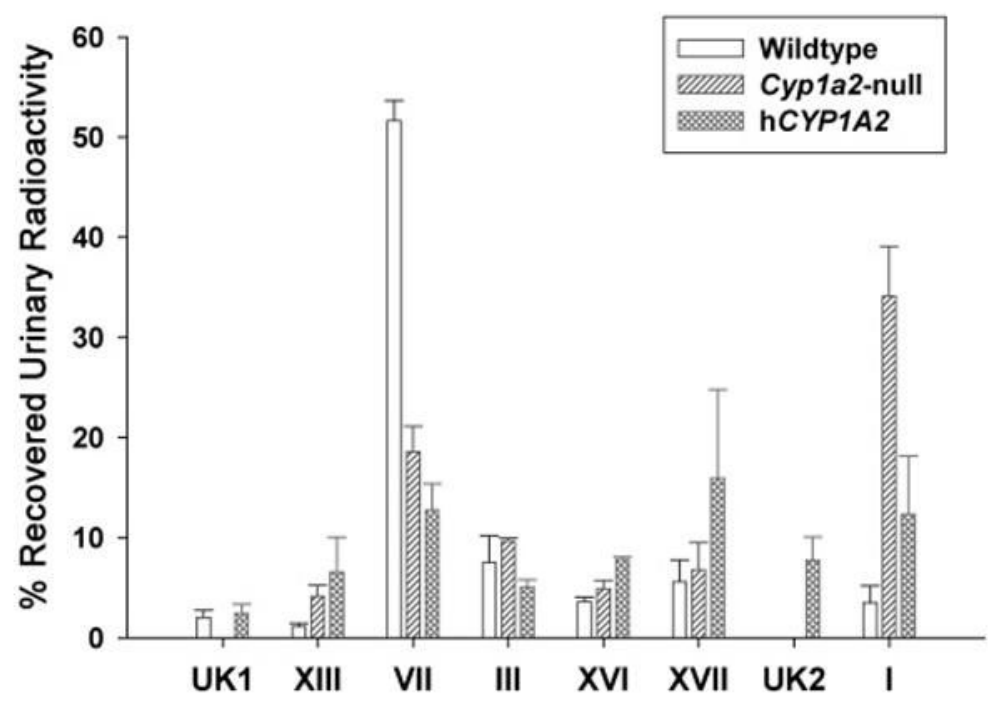

Figure 5.

Relative abundances of radiolabeled PhIP metabolites in mouse urine. Total recovered radioactivity from the $24 \mathrm{~h}$ urine samples of wild-type, Cypla2-null, and CYP1A2-humanized mice treated with $\left[{ }^{14} \mathrm{C}\right] \mathrm{PhIP}$ were set arbitrarily as $100 \%$. Relative abundance of each identified and unknown (UK) PhIP metabolite was calculated as the percentage of recovered urinary radioactivity $(n=4)$. 


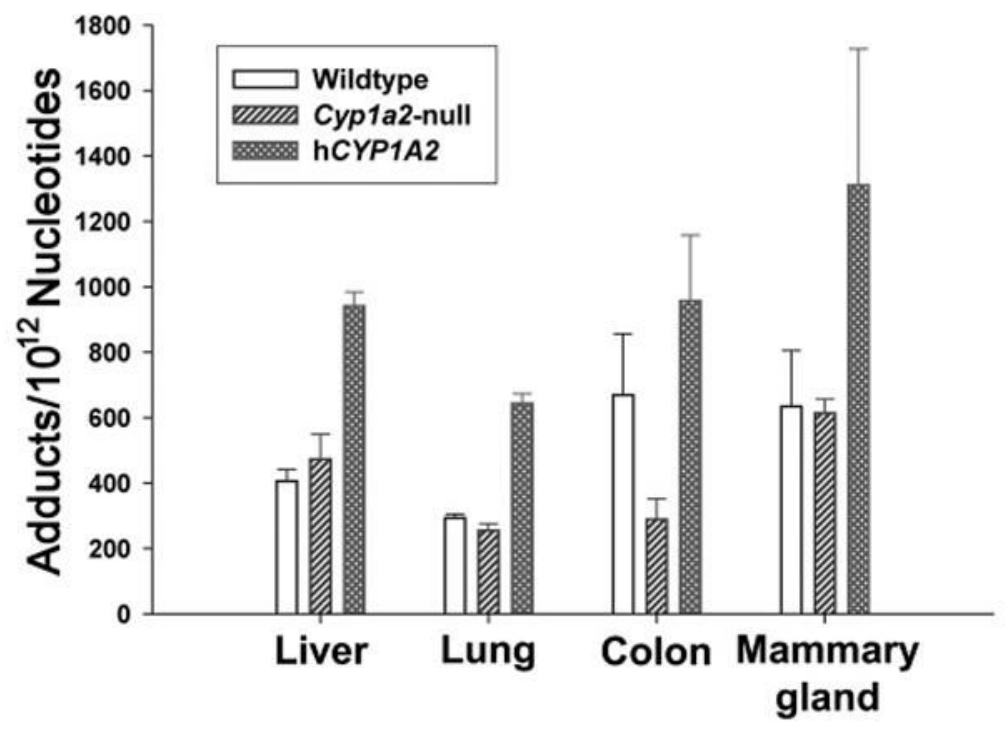

Figure 6.

DNA adduction level after PhIP treatment. DNA isolation and DNA adduct analysis following $\left[{ }^{14} \mathrm{C}\right] \mathrm{PhIP}$ dosing were described in the Experimental Procedures. DNA adduction levels in the liver, lung, colon, and mammary gland of wild-type, Cypla2-null, and CYP1A2-humanized mice were presented as the number of PhIP-DNA adducts per $10^{12}$ nucleotides $(n=4)$. 


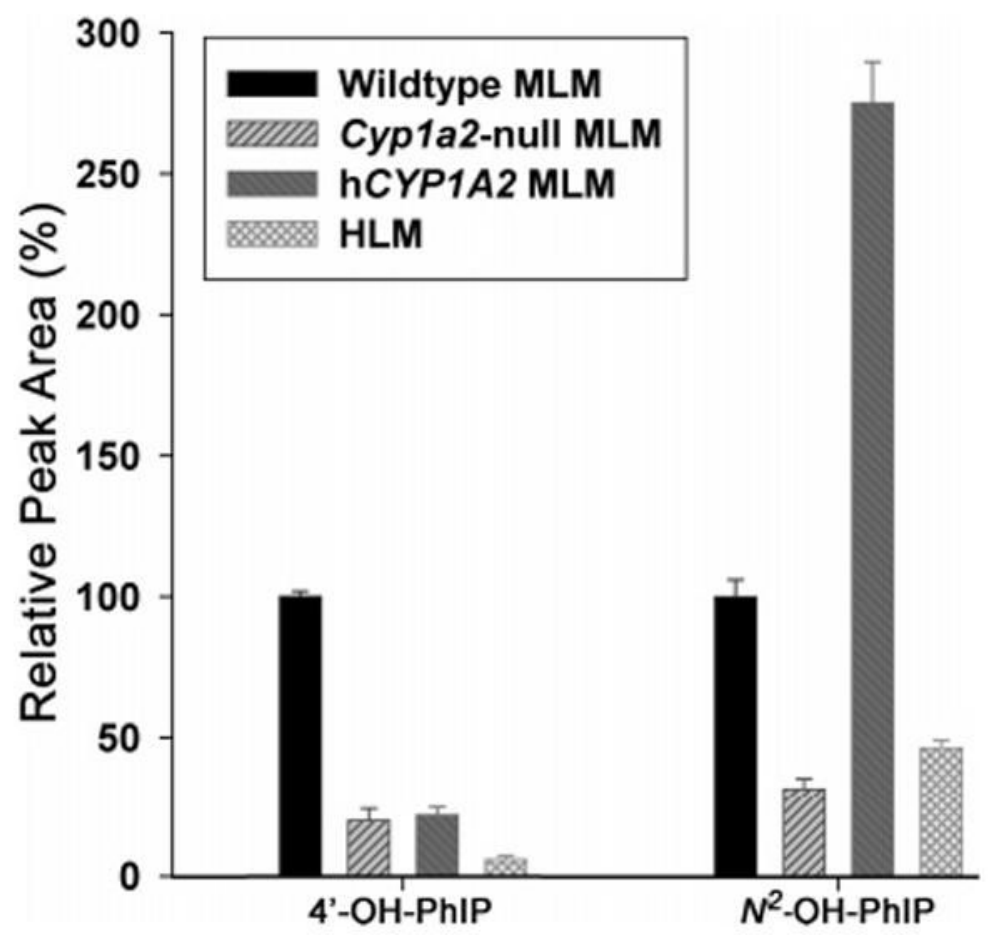

Figure 7.

In vitro oxidation of PhIP by MLM from wild-type, Cypla2- null, and CYP1A2- humanized mice and by pooled HLM. Relative 4'-hydroxylase and $N^{2}$-hydroxylase activities of MLMs and HLM were calculated by arbitrarily setting the yield of wild-type MLM as $100 \%(n=3)$. 

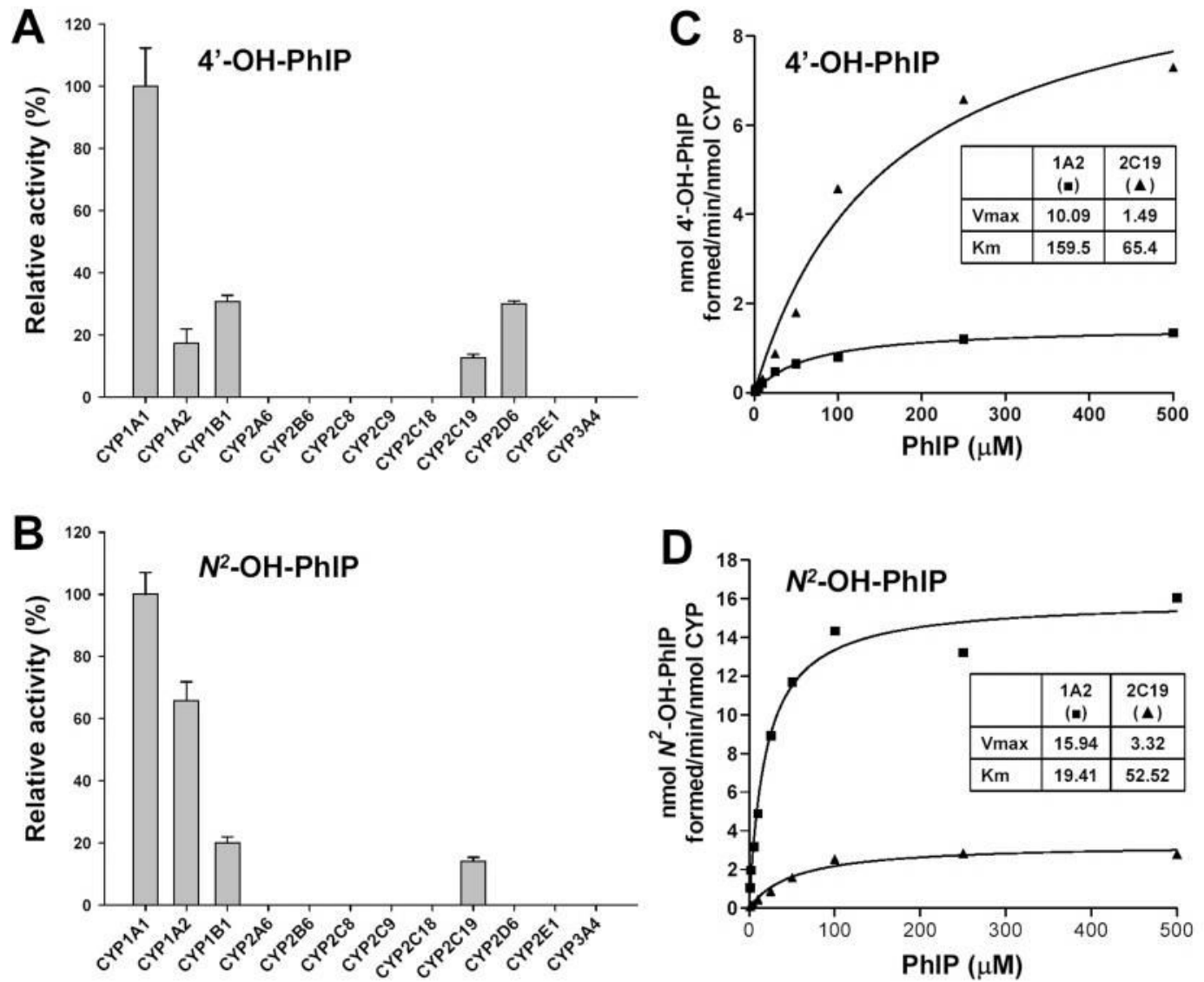

Figure 8.

Relative 4'-hydroxylase and $N^{2}$-hydroxylase activities of recombinant human P450s and enzyme kinetics of CYP1A2 and CYP2C19. (A) Relative activity of P450s for the generation of 4'-OH-PhIP. (B) Relative activity of P450s for the generation of $N^{2}-\mathrm{OH}-\mathrm{PhIP}$. The enzymatic activity of the P450 isozyme with the highest yield of targeted metabolite was set arbitrarily as $100 \%$. The relative activity was presented as the mean $\pm \mathrm{SD}(n=3)$. (C) Enzyme kinetics of recombinant human CYP1A2 (घ) and CYP2C19 ( $\boldsymbol{\Delta})$ on the formation of 4'-OHPhIP. (D) Enzyme kinetics of recombinant human CYP1A2 ( $\boldsymbol{\bullet})$ and CYP2C19 ( $\boldsymbol{\Delta})$ on the formation of $N^{2}-\mathrm{OH}-\mathrm{PhIP}$. 

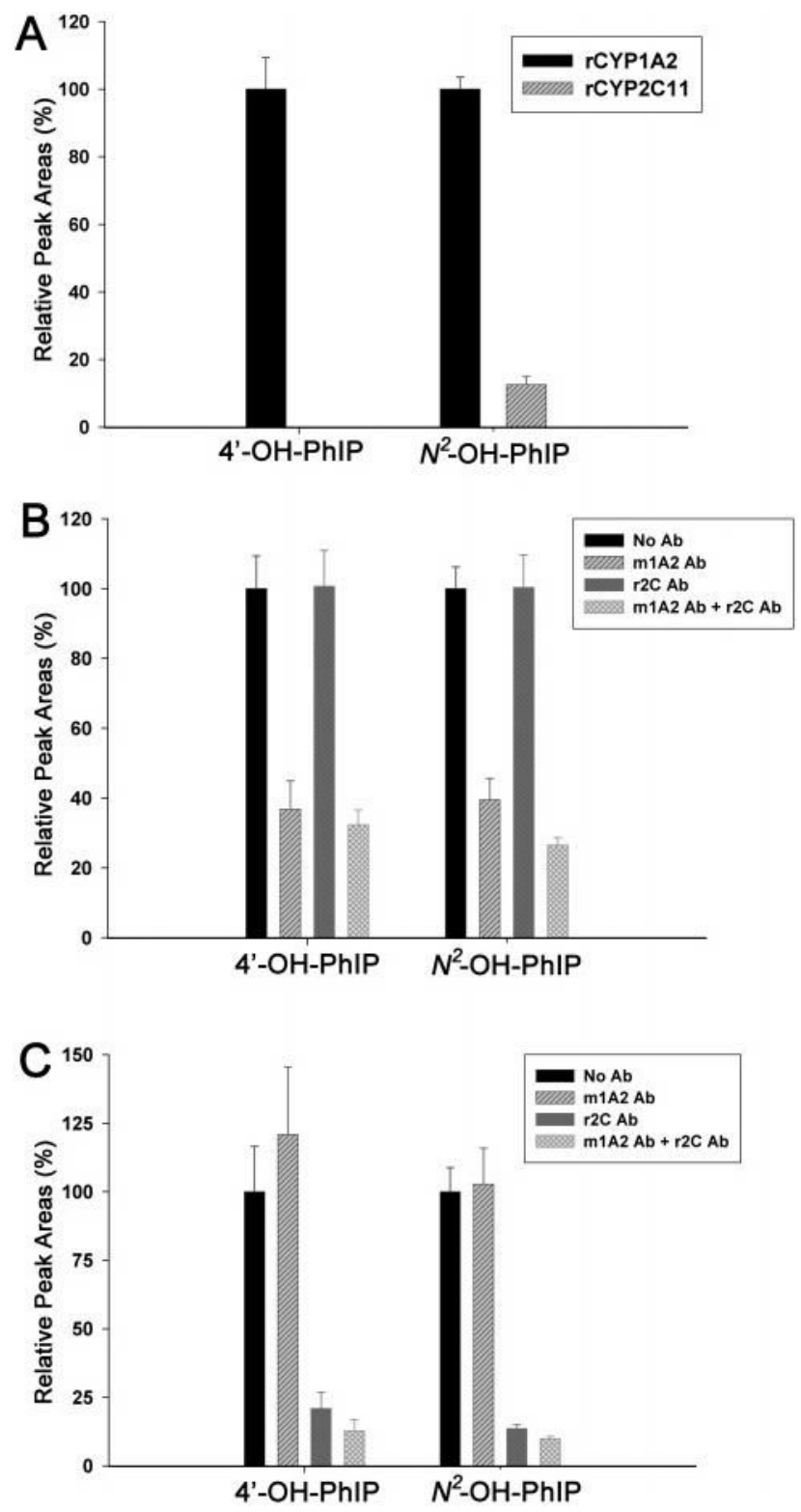

Figure 9.

Inhibition of in vitro microsomal oxidation of PhIP by CYP1A2 and CYP2C antibodies. (A) Relative activity of rat CYP1A2 and rat CYP2C11 for the generation of 4'-OH-PhIP and $\mathrm{N}^{2}$ $\mathrm{OH}-\mathrm{PhIP}$. (B) Influence of anti-mCYP1A2 and anti-rCYP2C11 mAbs on the formation of 4'$\mathrm{OH}-\mathrm{PhIP}$ and $N^{2}-\mathrm{OH}-\mathrm{PhIP}$ by wild-type MLM. (C) Influence of anti-mCYP1A2 and antirCYP2C11 mAbs on the formation of 4'-OH-PhIP and $N^{2}-\mathrm{OH}-\mathrm{PhIP}$ by Cypla2-null MLM. The peak area of target metabolites from an antibody-free incubation was set arbitrarily as $100 \%(n=3)$. 


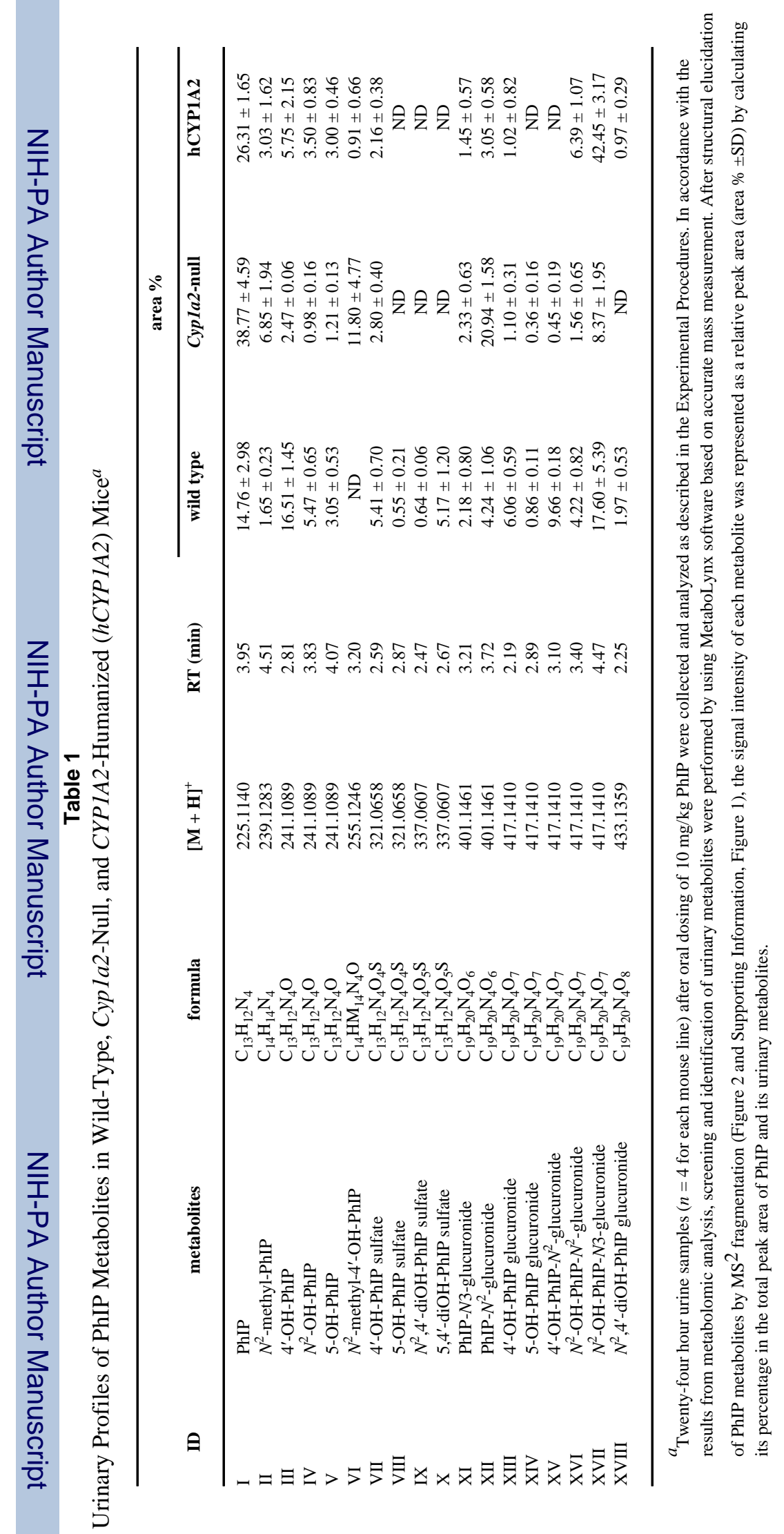

Chem Res Toxicol. Author manuscript; available in PMC 2007 April 10. 